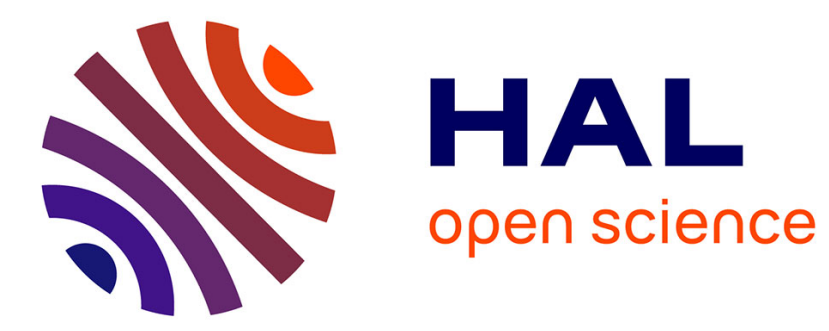

\title{
In vivo sodium release and saltiness perception in solid lipoprotein matrices. 2. Impact of oral parameters
}

Genica G. Lawrence, Chantal C. Septier, Christine C. Achilleos, Philippe P. Courcoux, Christian Salles

\section{- To cite this version:}

Genica G. Lawrence, Chantal C. Septier, Christine C. Achilleos, Philippe P. Courcoux, Christian Salles. In vivo sodium release and saltiness perception in solid lipoprotein matrices. 2. Impact of oral parameters. Journal of Agricultural and Food Chemistry, 2012, 60 (21), pp.5299-5306. 10.1021/jf204435f . hal-00939517

\section{HAL Id: hal-00939517 https://hal.science/hal-00939517}

Submitted on 28 May 2020

HAL is a multi-disciplinary open access archive for the deposit and dissemination of scientific research documents, whether they are published or not. The documents may come from teaching and research institutions in France or abroad, or from public or private research centers.
L'archive ouverte pluridisciplinaire HAL, est destinée au dépôt et à la diffusion de documents scientifiques de niveau recherche, publiés ou non, émanant des établissements d'enseignement et de recherche français ou étrangers, des laboratoires publics ou privés. 


\title{
In Vivo Sodium Release and Saltiness Perception in Solid Lipoprotein Matrices. 2. Impact of Oral Parameters
}

\author{
Génica Lawrence, ${ }^{\dagger, \ddagger}, \#$ Chantal Septier, ${ }^{\dagger,+\#}$ Christine Achilleos, ${ }^{\S}$ Philippe Courcoux, ${ }^{\otimes}$ \\ and Christian Salles ${ }^{*},+,+, \#$ \\ ${ }^{\dagger}$ CNRS, UMR6265 CSGA, F-21000 Dijon, France \\ ${ }^{\ddagger}$ INRA, UMR1324 CSGA, F-21000 Dijon, France \\ \#Université de Bourgogne, F-21000 Dijon, France \\ ${ }^{\S}$ INRA, UR342 Technologie et Analyses Laitières, F-39800 Poligny, France \\ ${ }^{\otimes}$ ONIRIS, Unité de Sensométrie et Chimiométrie, F-44322 Nantes, France
}

\begin{abstract}
This study aimed to investigate the relationships between sodium release, saltiness, and oral parameters during the eating of lipoprotein matrices (LPM). Sodium release and saltiness relative to 10 LPM were recorded during normal mastication by five subjects with differing oral parameters (chewing efficiency and salivary flow rate). The LPM samples varied in composition (dry matter, fat, salt, and $\mathrm{pH}$ levels) and represented a broad range of hardness. Mastication was recorded using electromyography simultaneously with sensory assessment. Differences in chewing behavior could explain most of the variability in sodium release and saltiness among subjects. Subjects with a higher chewing force and lower salivary flow rate experienced higher levels of sodium release and saltiness. In terms of the LPM, sodium release and saltiness were affected by either chewing behavior or food composition.
\end{abstract}

KEYWORDS: sodium release, saltiness, lipoprotein matrices, electromyography

\section{INTRODUCTION}

Flavor release and flavor perception are important for both the food industry and consumers. ${ }^{1}$ Indeed, a clearer understanding of the mechanisms involved in modifications to sodium release, and consequently to saltiness perception when the food composition and texture change, should allow modulating inmouth salt release during the consumption of low-salt foods. Taste perceptions from foods are strongly dependent on a dynamic and complex relationship between the physical and chemical properties of the product ${ }^{2}$ and the oral physiological behavior of the consumer. ${ }^{3}$ In a previous study, ${ }^{4}$ the physical and chemical aspects of sodium release and saltiness perception during the eating of lipoprotein matrices varying in terms of their dry matter content (DM), fat to DM ratio (fat/DM), salt contents, or $\mathrm{pH}$ levels were investigated. The variations in salt, dry matter, and fat levels affected texture and taste perceptions differently. As a function of salt content, temporal sodium release and saltiness perception were differently affected by composition and textural changes. We particularly observed individual differences between subjects characterized by differences in oral release and saltiness perception. The aim of the present study was thus to investigate the influence of individual oral physiology on temporal sodium release and saltiness perception when lipoprotein matrices are eaten.

Mastication is one of the oral physiological factors that affect flavor release in the mouth. ${ }^{3}$ It is a process during which pieces of food are ground into a fine state, mixed with saliva, and then transferred to the stomach, where most of the digestion occurs. Mastication is a complex process resulting from rhythmic activity of the jaw opening and closing muscles regulated by a central pattern generator. ${ }^{3}$ Masticatory behavior differs from one individual to another. Analyses of masticatory recordings have revealed intersubject variance to be greater than intrasubject variance. ${ }^{5,6}$ These differences in masticatory behavior can alter the degree and balance of both aroma and taste compounds released. Rapid sodium release has been linked to high bite force, whereas slower sodium release is connected to a long chewing sequence duration. ${ }^{7}$ Masticatory behavior can also vary as a function of food texture and composition. The hardness of a food is a key factor affecting chewing activity. Numerous publications have reported that total muscle work, the number of chewing strokes, and burst duration measured by electromyography (EMG) increase in line with the hardness of samples. ${ }^{8-11}$ The consumption of eight model cheeses with differing properties resulted in different chewing and aroma release patterns, ${ }^{11}$ suggesting that chewing behavior could explain most of the variability in aroma release among subjects. Aroma release increased in line with chewing work, the number of bursts, and amplitude. With cheese samples, chewing behavior varied according to texture. $^{7,11,12}$ The combined effects of cheese composition and chewing behavior affected aroma release: a lower fat content or higher hardness of the product thus increased chewing activity, which is turn increased aroma release. ${ }^{11}$ The authors concluded that composition influenced the texture of the product, which is turn influenced the chewing pattern, whereas both influenced aroma release.

Received: November 4, 2011

Revised: April 25, 2012

Accepted: April 30, 2012

Published: April 30, 2012 
Saliva is another oral physiological factor that affects flavor release. Saliva is a mixed heterogeneous fluid secreted by three major salivary glands (90\%) and other minor glands $(10 \%){ }^{13}$ The flow rate and composition of saliva differ from one individual to another and are affected by the degrees of hydration, olfaction, and stimulation. ${ }^{14}$ The considerable complexities of the relationships between saliva and taste perception are not yet fully understood. Studies of saliva and taste have resulted in various conclusions. It has been shown that the long period required to attain the concentration of sodium released in the mouth $\left(T_{\max }\right)$ could be related to a low salivary flow rate during the eating of a model cheese matrix. ${ }^{6} \mathrm{~A}$ high salivary flow rate has been linked to high sodium release and the rate of saltiness perception, but tended to be independent of saltiness intensity when model cheeses were eaten. ${ }^{7}$ For other tastes, subjects with high salivary flow rates took a significantly longer time to reach the maximum perceived intensity of sweetness compared with subjects with a low flow rate. ${ }^{15}$ However, the salivary flow rate did not affect the maximum perceived intensity of a cherry flavor gum or total time required to reach this level. Low-flow subjects experience a longer persistence of bitterness and astringency. ${ }^{16}$

In the present study, subjects with different masticatory performances and salivary flow rates were selected. By monitoring chewing activity, temporal saltiness perception (discontinuous method), and in-mouth sodium release to follow temporal sodium and saltiness perceptions, the relationships between eating behavior, sodium release, and saltiness perception were investigated.

\section{MATERIALS AND METHODS}

All of the abbreviations are listed in Table 1.

Product Preparation. Among the 18 lipoprotein matrices (LPM) that could mimic a hard type of cheese, ${ }^{4} 10$ LPM were prepared for this study. The set of 10 LPM corresponds to an optimal experimental design, generated by the Fedorov algorithm (SAS software, SAS Institute Inc., Cary, NC, USA). These samples varied as follows: (i) two DM levels ( 370 and $440 \mathrm{~g} / \mathrm{kg}$ ), (ii) two fat to DM ratios (20 and $40 \%$ ), (iii) two sodium chloride levels ( 0.5 and $1.5 \%$ ), and (iv) two $\mathrm{pH}$ levels (6.2 and 6.5). The preparation of these products is reported in detail elsewhere. ${ }^{4}$ The conditions for the production of the 10 LPM are presented in Table 2.

Rheological Properties. LPM rheological properties were determined by uniaxial compression with a TA-XT2 texture analyzer (Stable, Micro Systems Ltd., Champlan, France). ${ }^{4}$ The work to fracture (Wf) is the parameter used to represent hardness property.

Selection of Subjects. From a panel of 15 subjects, 5 subjects (3 women, 2 men; overall mean age $=32$ years) with natural dentition were selected for their oral physiology performance and good representativeness of different oral behaviors (different combinations in high/low salivary flow rate and high/low masticatory performance). The salivary flow rate at rest and under stimulated conditions, ${ }^{17}$ masticatory performance, ${ }^{5}$ and sensitivity to salty taste ${ }^{7}$ were measured in each subject. The protocols used to determine salivary flow rate and masticatory performance are presented below. In the selection of subjects for this study, the measurements for all 15 panel members were determined at the same time of day because saliva composition and flow rate evolve during the day. ${ }^{18,19}$ Written informed consent was obtained from each subject after they had received a brief explanation of the experiment.

Masticatory Performance. Optosil dental silicone (Perrigot et Cie, Dijon, France) $(\varnothing=1.4 \mathrm{~cm} ; h=1.8 \mathrm{~cm} ; m=3.30 \pm 0.05 \mathrm{~g})$ was used to evaluate masticatory performance (MP). After 20 chewing cycles with this material, the subjects were asked to spit the sample into a coffee filter and to rinse their mouths with water. The rinsing water was also collected in the filter. This experiment was repeated
Table 1. Abbreviations

\begin{tabular}{|c|c|c|}
\hline \multicolumn{2}{|c|}{ abbreviation } & lipoproteic matrices (LPM) \\
\hline \multicolumn{2}{|c|}{$\mathrm{p} 1$ or S3D2F2P2 } & salt $1.5 \%-\mathrm{DM} 440 \mathrm{~g}-$ fat/DM $40 \%-\mathrm{pH} 6.5$ \\
\hline \multicolumn{2}{|c|}{$\mathrm{p} 3$ or S3D2F1P2 } & salt $1.5 \%-\mathrm{DM} 440 \mathrm{~g}-\mathrm{fat} / \mathrm{DM} 20 \%-\mathrm{pH} 6.5$ \\
\hline \multicolumn{2}{|c|}{$\mathrm{p} 4$ orS3D1F2P1 } & salt $1.5 \%-\mathrm{DM} 370 \mathrm{~g}-\mathrm{fat} / \mathrm{DM} 40 \%-\mathrm{pH} 6.2$ \\
\hline \multicolumn{2}{|c|}{ p5 or S3D2F1P1 } & salt $1.5 \%-\mathrm{DM} 440 \mathrm{~g}-\mathrm{fat} / \mathrm{DM} 20 \%-\mathrm{pH} 6.2$ \\
\hline \multicolumn{2}{|c|}{ p6 or S3D1F1P1 } & salt $1.5 \%-\mathrm{DM} 370 \mathrm{~g}-\mathrm{fat} / \mathrm{DM} 20 \%-\mathrm{pH} 6.2$ \\
\hline \multicolumn{2}{|c|}{ p14 or S1D1F2P2 } & salt $0.5 \%-\mathrm{DM} 370 \mathrm{~g}-\mathrm{fat} / \mathrm{DM} 40 \%-\mathrm{pH} 6.5$ \\
\hline \multicolumn{2}{|c|}{ p15 or S1D1F1P2 } & salt $0.5 \%-\mathrm{DM} 370 \mathrm{~g}-\mathrm{fat} / \mathrm{DM} 20 \%-\mathrm{pH} 6.5$ \\
\hline \multicolumn{2}{|c|}{ p16 or S1D2F2P1 } & salt $0.5 \%-\mathrm{DM} 440 \mathrm{~g}-\mathrm{fat} / \mathrm{DM} 40 \%-\mathrm{pH} 6.2$ \\
\hline \multicolumn{2}{|c|}{$\mathrm{p} 17$ or S1D2F1P1 } & salt $0.5 \%-\mathrm{DM} 440 \mathrm{~g}-\mathrm{fat} / \mathrm{DM} 20 \%-\mathrm{pH} 6.2$ \\
\hline \multicolumn{2}{|c|}{ p18 or S1D1F1P1 } & salt $0.5 \%-\mathrm{DM} 370 \mathrm{~g}-\mathrm{fat} / \mathrm{DM} 20 \%-\mathrm{pH} 6.2$ \\
\hline \multicolumn{2}{|l|}{$\mathrm{DM}$} & dry matter $(\mathrm{g})$ \\
\hline \multicolumn{2}{|l|}{ Wf } & work to fracture $\left(\mathrm{kJ} / \mathrm{m}^{3}\right)$ \\
\hline \multicolumn{2}{|l|}{ abbreviation } & oral parameter \\
\hline \multicolumn{2}{|l|}{ SF } & salivary flow rate $(\mathrm{mL} / \mathrm{min})$ \\
\hline \multicolumn{2}{|l|}{ MP } & masticatory performance \\
\hline \multicolumn{2}{|l|}{$\mathrm{BN}$} & number of bursts \\
\hline \multicolumn{2}{|l|}{$\mathrm{BD}$} & burst duration $(s)$ \\
\hline \multicolumn{2}{|l|}{$\mathrm{Vm}$} & mean amplitude of muscle contraction $(\mathrm{mV})$ \\
\hline \multicolumn{2}{|l|}{ Vmax } & maximum amplitude of muscle contraction $(\mathrm{mV})$ \\
\hline \multicolumn{2}{|l|}{ Wtot } & total muscle work $(\mathrm{mV} \cdot \mathrm{s})$ \\
\hline \multicolumn{2}{|l|}{ abbreviations } & sodium release and sensory parameters \\
\hline slopeR1 & \multicolumn{2}{|c|}{$\begin{array}{l}\text { initial increasing slope for in-mouth sodium release } \\
(\mathrm{g} / 100 \mathrm{~g} \text { saliva/s) }\end{array}$} \\
\hline slopeI1 & \multicolumn{2}{|c|}{ initial increasing slope for in-mouth saltiness $(\mathrm{AU} / \mathrm{s})$} \\
\hline Cmax & \multicolumn{2}{|r|}{ maximum in-mouth sodium concentration $(\mathrm{g} / 100 \mathrm{~g}$ saliva $)$} \\
\hline $\operatorname{Imax}$ & \multicolumn{2}{|c|}{ maximum saltiness intensity (AU) } \\
\hline TRmax & \multicolumn{2}{|c|}{ time when Cmax is reached $(s)$} \\
\hline TImax & \multicolumn{2}{|c|}{ time when Imax is reached $(\mathrm{s})$} \\
\hline slopeR2 & \multicolumn{2}{|c|}{$\begin{array}{l}\text { decreasing slope for in-mouth sodium release } \\
(\mathrm{g} / 100 \mathrm{~g} \text { saliva } / \mathrm{s})\end{array}$} \\
\hline slopeI2 & \multicolumn{2}{|r|}{ decreasing slope for in-mouth saltiness perception $(\mathrm{AU} / \mathrm{s})$} \\
\hline $\mathrm{s} 1, \mathrm{~s} 2, \ldots$ & & 1 , suopect $2, . .$. \\
\hline
\end{tabular}

three times. Particles of the sample were dried for overnight at room temperature and passed through a sieve with a mesh size of $4 \mathrm{~mm}$. The masticatory efficiency of each subject was defined as the weight of Optosil particles that passed through the sieve versus the weight of chewed sample.

Salivary Flow Rate Measurements. The subjects were asked not to drink, eat, or smoke for 90 min before the tests. The overall salivary flow rate (SF) was measured. ${ }^{17}$ The saliva was collected using the spitting method, at rest and following the mechanical stimulation of salivation. Prior to collection, the mouth was emptied by an initial swallow.

At rest, the panelists were asked to spit out the saliva they produced at $30 \mathrm{~s}$ intervals over a $5 \mathrm{~min}$ period. Stimulated saliva was obtained by chewing on a piece of paraffin wax $(0.5 \pm 0.02 \mathrm{~g}$, Parafilm "M" American National Can, Chicago, IL, USA) for 1 min (spitting out their saliva every $30 \mathrm{~s}$ ). The results on salivary flow rate corresponded to six replicate measurements performed during the same hour that the subjects carried out the test. As the specific density of saliva is close to 1.0 , the weight of saliva was assumed to equal the volume of saliva secreted. Thus, salivary flow rates measured at rest and under stimulation were expressed in milliliters per minute. After the five final subjects had been selected, further salivary flow rate measurements were performed concomitantly with the other measurement sessions (temporal saltiness measurements).

Muscle Activity Recording by Electromyography (EMG). EMG analyses were performed concomitantly with temporal saltiness measurements. Throughout the chewing of $5 \mathrm{~g}$ of LPM, variations in the muscle activity of the jaws were followed using EMG. ${ }^{20}$ Gold surface electrodes (Grass Telefactor AStro-Med, USA) coated with 


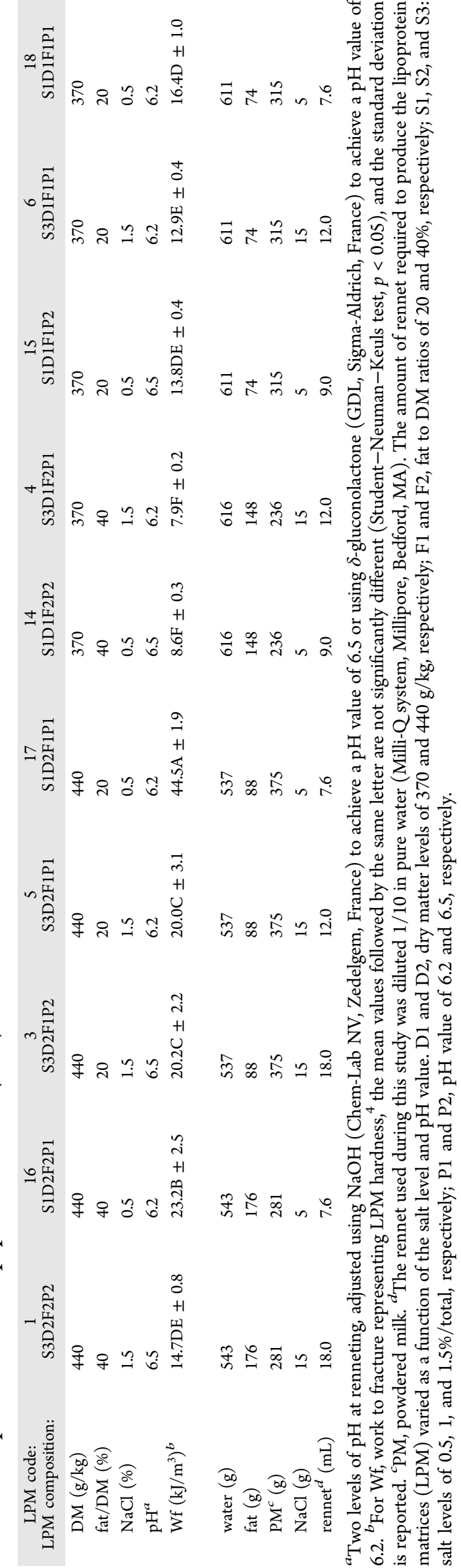

conductive gel were placed on the left and right superficial masseter and anterior temporalis muscles. The electrical signal, resulting from nerve cells and which cause muscle contraction during chewing, was recorded using Spike 2 data collection software (Cambridge Electronic Design, U.K.), and rectified EMG signals were analyzed. ${ }^{20}$ The EMG parameters analyzed to characterize chewing activity were the burst duration (closing phase of each cycle, BD) and the mean and maximum amplitudes of muscle contraction measured for each burst ( $\mathrm{Vm}$ and Vmax, respectively; expressed in $\mathrm{mV}$ ). These values were collected from each of the four muscles and averaged. The chewing sequence was characterized by the number of bursts (BN) and the total muscle work (Wtot, expressed in $\mathrm{mV} \cdot \mathrm{s}$ ). Three replicates were performed for each product.

Temporal Sodium Release and Saltiness Measurements. Sodium release and saltiness perception patterns during the eating of the LPM were obtained from each of the five subjects. ${ }^{4}$ For each subject, measurements were done at a fixed time in each day.

Data Analyses. Parameters of the time-intensity curves (temporal sodium release and saltiness) were defined: slopeR1 and slopeI1 (for sodium release and saltiness, respectively), the initial slope of the curve measured between 0 and $20 \mathrm{~s}$, corresponding to the period of partial product breakdown; the Cmax and Imax (for sodium release and saltiness, respectively), representing the maximum concentration or intensity values attained; TRmax and TImax (for sodium release and saltiness, respectively), the time required to reach the Cmax and Imax, and slopeR2 and slopeI2 (for sodium release and saltiness, respectively). The downward slope calculated from the Cmax or Imax corresponded to the persistence of sodium or taste in the mouth, respectively.

Analyses of variance (ANOVA) were performed using Statgraphics Centurion XV.I software (version 15.2, Sigma-Plus, France). When a significant effect $(p<0.05)$ was revealed by applying ANOVA, the Student-Newman-Keuls test was used to compare the differences in least-squares (LS) means. Principal component analysis (PCA) was used to study the variability of EMG parameters and was carried out using Uniwin Plus (version 6.1, Sigma-Plus, France). Partial leastsquares regression (PLS) was used to study the relationships between oral parameters (number of bursts, burst duration, mean and maximum amplitudes of muscle contraction, muscle work per chewing cycle, masticatory performance, and salivary flow rate), LPM characteristics, and sodium release and saltiness parameters. PLS was performed using Statgraphics Centurion XV.I software (version 15.2, Sigma-Plus, France).

\section{RESULTS AND DISCUSSION}

Characterization of the Panel. The five subjects displayed significantly different stimulated salivary flow rates $(p<0.001)$. The range of variation extended from 0.9 to $2.6 \mathrm{~mL} / \mathrm{min}$. Individual differences in salivary flow rates with similar ranges (from 0.3 to $2.4 \mathrm{~mL} / \mathrm{min}$ and from 0.4 to $3.9 \mathrm{~mL} / \mathrm{min}$, respectively) have previously been reported. ${ }^{5,21}$ Post hoc comparisons showed that two subjects had a similarly high salivary flow rate (s1 and s2), whereas the other three subjects had a similarly low salivary flow rate $(\mathrm{s} 3-\mathrm{s} 5)$. The means obtained for each subject are presented in Table 3. No significant differences between the subjects were observed with regard to the salivary flow rate at rest (mean $=0.5 \pm 0.07 \mathrm{~mL}$ / $\min$ ).

ANOVA revealed significant differences between the five subjects with regard to their masticatory performance ( $p=$ 0.0015 ). Post hoc comparisons showed that subjects 5 and 1 had a similar and relatively high chewing efficiency, whereas it was weak in subjects 2-4, although there were significant differences between these latter three subjects. Subject 4 displayed significantly low chewing efficiency (Table 3 ).

Product Hardness. Four-way ANOVA (DM, fat, salt, and $\mathrm{pH}$ levels as fixed factors) revealed significant differences in 
Table 3. Mean and Standard Deviation of the Salivary Flow Rates and Chewing Efficiencies of the Five Subjects ${ }^{a}$

\begin{tabular}{cccccc} 
& \multicolumn{2}{c}{ salivary flow rate $^{b}(\mathrm{~mL} / \mathrm{min})$} & & \multicolumn{2}{c}{ masticatory performance (\%) } \\
\cline { 2 - 3 } \cline { 5 - 6 } & mean & level $^{c}$ & & mean & level $^{c}$ \\
s1 & $2.2 \pm 0.4 \mathrm{~b}$ & + & & $41.86 \pm 5.23 \mathrm{a}$ & + \\
s2 & $2.6 \pm 0.3 \mathrm{a}$ & + & & $30.82 \pm 5.23 \mathrm{~b}$ & - \\
s3 & $1.6 \pm 0.2 \mathrm{c}$ & - & & $20.24 \pm 5.23 \mathrm{~b}$ & - \\
s4 & $0.9 \pm 0.3 \mathrm{~d}$ & - & & $3.04 \pm 5.23 \mathrm{c}$ & - \\
s5 & $1.5 \pm 0.2 \mathrm{c}$ & - & & $50.98 \pm 5.23 \mathrm{a}$ & +
\end{tabular}

${ }^{a}$ Different letters in the same column indicate that the means are different at $p<0.05$ (Student-Newman-Keuls test). ${ }^{b}$ Under mechanical stimulation. ${ }^{c}(+)$ subject presents a high level in the considered oral parameter; $(-)$ subject presents a low level in the considered oral parameter.

hardness among the 10 LPM (Table 2). ANOVA revealed a significant influence of all composition factors. High hardness values were observed for high DM content $(p<0.001)$ and for low fat content $(p<0.001)$, salt contents $(p<0.001)$, and $\mathrm{pH}$ level $(p<0.05)$. Significant salt $\times$ DM content $(p<0.001)$ and salt $\times$ fat/DM $(p<0.05)$ interactions were also found, showing the significant low effect of DM or fat/DM for the highest salt content. Variations in composition allowed us to obtain different structures for the LPM. A reduction in the DM content resulted in a softer LPM because of its lower protein content and consequently led to the formation of a less compact protein network. An increase in the fat content produced a softer LPM due to the reduction in the protein content and disruption of the protein network by fat droplets, as previously reported. ${ }^{22} \mathrm{An}$ increase in the salt content and $\mathrm{pH}$ level produced softer LPM, which was due to a partial inhibition of the action of chymosin (a rennet enzyme), which consequently limited casein coagulation phenomena. ${ }^{23-25}$

Chewing Activity. PCA was applied to the EMG parameters to study variations in the chewing behavior of all subjects and with all cheeses (Figure 1). The first component (component 1) accounting for 55\% of variance was positively correlated with mean and maximum amplitude (Vm and Vmax, respectively), SF, and the number of bursts (BN). Vm, Vmax, $\mathrm{SF}$, and MP appeared to be positively correlated, and these parameters appeared to be negatively correlated to $\mathrm{BN}$. Differences between subjects highlighted differences in chewing behavior. Component 1 separated subjects 1 and 5 , on the right-hand side, from subjects 3 and 4 on the left-hand side. Subjects 1 and 5 presented the highest masticatory performance values, whereas subjects 3 and 4 displayed the lowest masticatory performance values (Table 3 ) and low total work. Subjects 3 and 4 required greater work to eat the LPM samples. The second component (component 2) accounted for 33\% of total variance and was mainly associated with burst duration (BD). BD appeared positively correlated to $\mathrm{BN}$ and negatively correlated to MP. Subject 4 had high burst duration that contrasted with that of subject 5 and 2 . These results are in line with others that had identified the parameters related to chewing work as being the most important parameters to explain differences in eating behavior between subjects. ${ }^{11}$

Relationships between Sodium Release, Saltiness Perception, and Oral Parameters. Marked individual differences were observed with respect to temporal sodium release and saltiness perception, ${ }^{4}$ which is in agreement with previous findings. ${ }^{7,26}$ An example of curves showing differences relative to the temporal sodium release and saltiness intensity

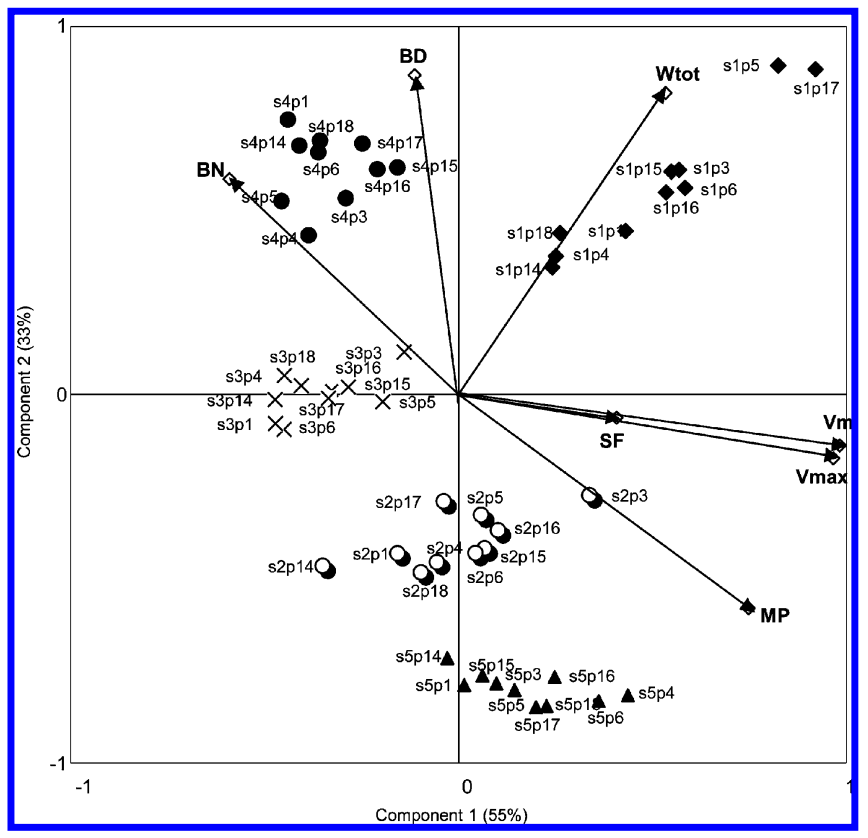

Figure 1. Principal component analysis biplot of chewing parameters obtained for each subject (s1-s5) and each product (p1, p3, p4, p5, p6, p14, p15, p16, p17, p18). Parameters: burst duration (BD), mean and maximum amplitudes (Vm and Vmax, respectively), total muscle work (Wtot), number of bursts (BN), salivary flow rate (SF), and masticatory performance (MP).

for the LPM S3D2F2P2 for the five subjects is presented in Figure 2. For each subject, the differences between sodium release and temporal saltiness patterns could be explained by differences in both saltiness sensitivity and oral behavior during the consumption of the LPM.

To determine parameters that could explain the variability observed in saltiness perception, a PLS regression was applied to the data on chewing parameters, sodium release parameters, product characteristics (block $\mathrm{X}$ ), and saltiness parameters (block Y). The first two components explained 59\% of the total variability relative to saltiness perception. The scores and variable loadings for the two components are shown in Figure 3. The variability in sodium release parameters was mainly related to the variability in chewing parameters and of food composition, mainly the salt content. Imax, slopeI1, Cmax, and slopeR1 were all positively correlated to chewing work in the first component, but negatively correlated in the second component. The first component mainly separated subjects according to their chewing force and their chewing speed. Subjects with a high chewing force (subjects 1 and 5) displayed the highest sodium release and saltiness perception values, the shortest time necessary to eat the sample (low $\mathrm{BN}$ ), the shortest time to reach peak sodium release and saltiness intensity (TRmax and TImax), and a shorter persistence of saltiness (slopeI2) in the mouth than subjects with a low chewing force (subjects 2-4). Subjects 1 and 5 chewed more rapidly than subjects $2-4$. The increase of sodium release with chewing force was probably due to the increase in the food matrix surface area due to sample breakdown. These findings are in agreement with other studies on in vivo and in vitro aroma and taste release. ${ }^{11,27,28}$ The second component separated subjects according to their salivary flow rate. Subjects with a low salivary flow rate reached higher Cmax and Imax values than subjects with a high salivary flow rate but over a 


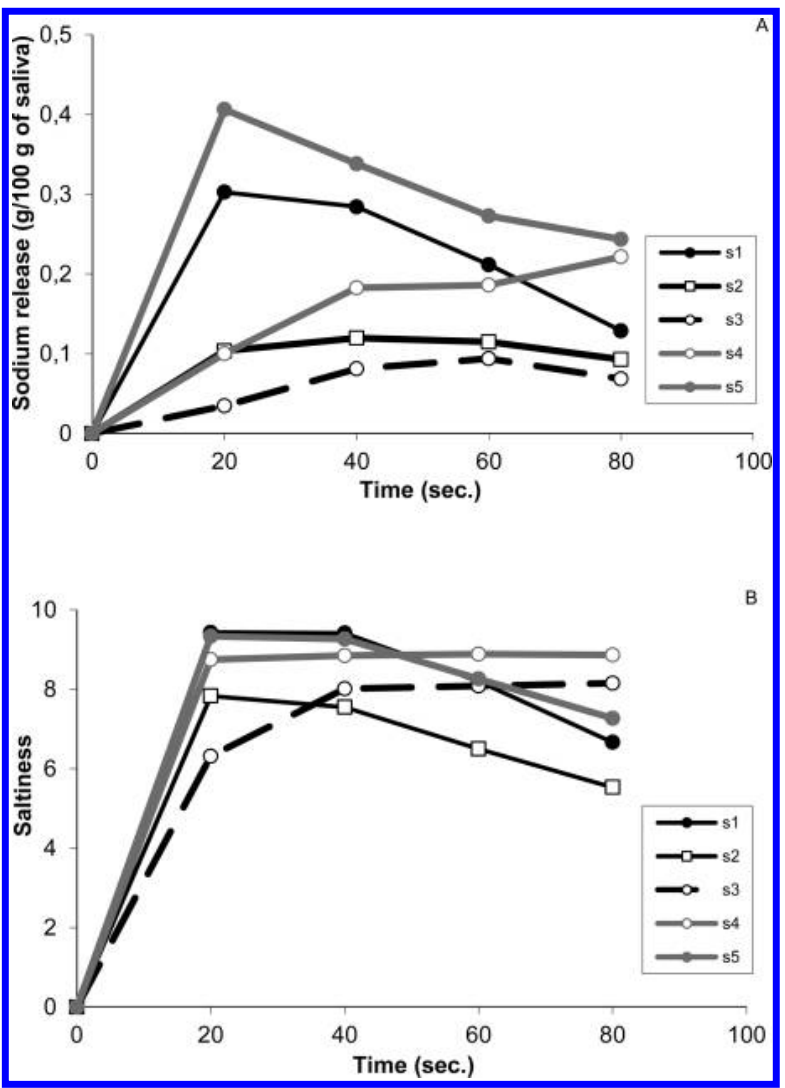

Figure 2. Average (of six replicates) of concentrations of sodium release in saliva (A) and saltiness (B) during eating of the lipoprotein matrices coded 1 (S3D2F2P2) .

longer period. A similar observation was already reported, showing significant decreases in perception with increasing salivary flow rates observed for citric acid and sodium chloride. ${ }^{29}$ Among the subjects with a low chewing force (subjects 2 and 4 ), subject 4 had the lowest salivary flow rate but displayed higher release and saltiness perception than subject 2 , who had a high salivary flow rate. These effects were also clearly observed in Figure 4 reporting a PLS regression conducted to explain saltiness and sodium release parameters by oral parameters. ANOVA confirmed these results and showed that sodium release was most influenced by chewing parameters, and saltiness parameters were most influenced by salivary flow rate (data not shown). We suggest that chewing activity is the key determinant of sodium release in the mouth, and the salivary flow rate is the key determinant of saltiness perception and saltiness persistence. The second component of the PLS mainly separated samples containing low and high salt levels. As expected, samples with a high salt content (1.5\%) had a higher sodium release and a higher saltiness intensity and were less firm than samples with a low salt content $(0.5 \%){ }^{4}$ These softer products required less chewing force to be masticated.

Moreover, it appeared that the concentration of sodium ions in saliva at rest, without any stimulation, could be related to saltiness intensity. Subjects 3 and 4, whose saliva at rest contained a higher sodium ion concentration, displayed higher values for maximum saltiness intensity, whereas subjects 2 and 5 , whose saliva at rest contained a lower sodium ion concentration, displayed lower values for maximum saltiness intensity $(t$ tests, $p<0.05)$. This finding needs to be verified in a larger panel. However, the finding suggests that saliva at rest could be an indicator of the saltiness sensitivity of an individual.

Relationships between Sodium Release, Saltiness, LPM Characteristics, and Chewing Behavior. For each subject, Figures 1 and 3 show differences between chewing behaviors, which we hypothesize are due to differences in the structure and composition of the LPM samples. To confirm this

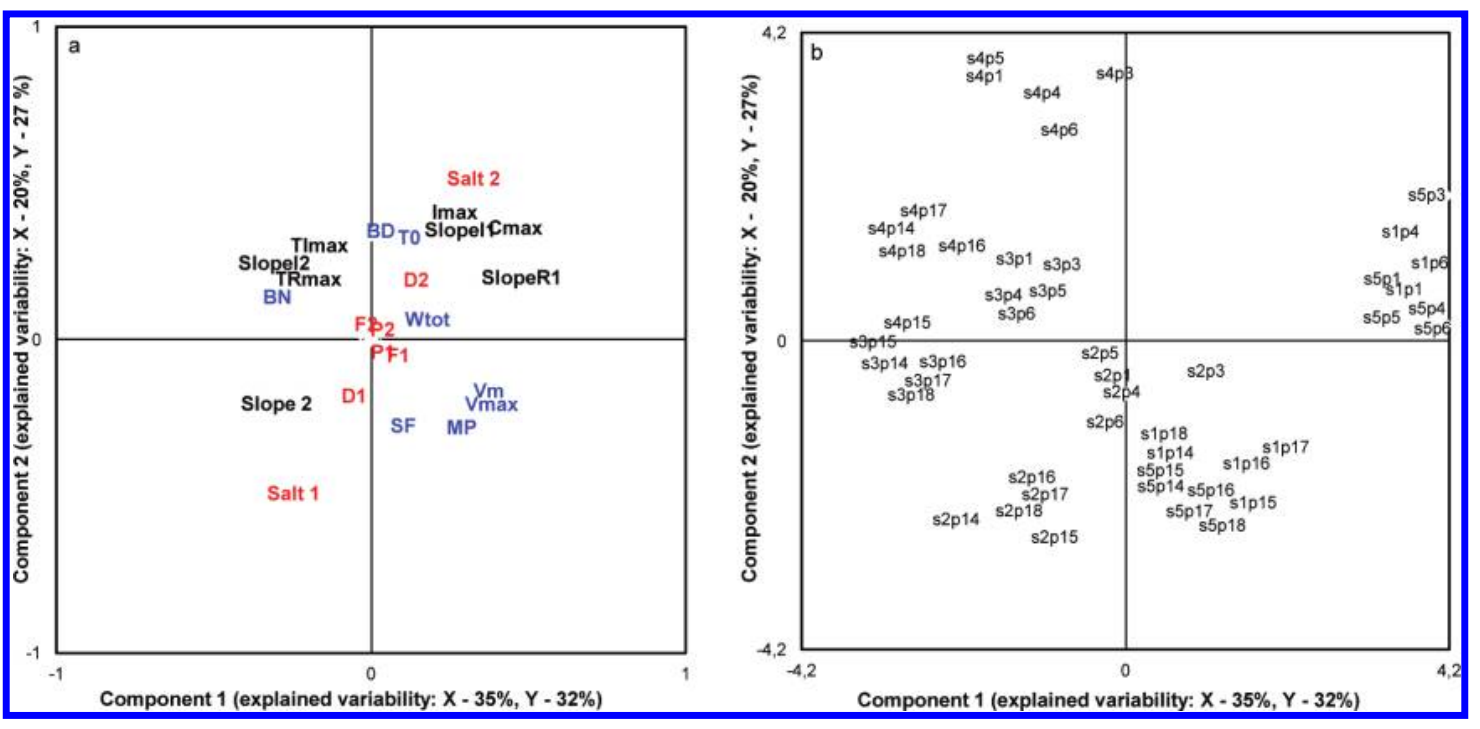

Figure 3. Partial least-squares method explaining saltiness parameters in terms of chewing parameters and lipoprotein matrix characteristics: (a) variable distribution plot; (b) scores plot for each lipoprotein matrix (p1, p3, p4, p5, p6, p14, p15, p16, p17, p18) and subject (s1-s5). Parameters: burst duration (BD), mean and maximum amplitudes (Vm and Vmax, respectively), total muscle work (Wtot), number of bursts (BN), salivary flow rate $(\mathrm{SF})$, masticatory performance $(\mathrm{MP})$, maximum sodium release (Cmax), maximum saltiness (Imax), time to reach the maximum sodium concentration (TRmax), time to reach maximum saltiness (TImax), initial sodium released between 0 and $20 \mathrm{~s}$ (slopeR1), initial saltiness between 0 and $20 \mathrm{~s}$ (slopeI1), persistence of sodium in saliva (slopeR2), persistence of saltiness (slope2), amount of sodium ions in the saliva at rest (T0), salt 2 (1.5\% salt content), salt 1 (0.5\% salt content). D2, DM at $440 \mathrm{~g} / \mathrm{kg}$; D1, DM at $370 \mathrm{~g} / \mathrm{kg}$; F2, fat to DM (40\%); F1, fat to dry matter (20\%); P2, pH at $6.5 ; \mathrm{P} 1, \mathrm{pH}$ at 6.2 . 


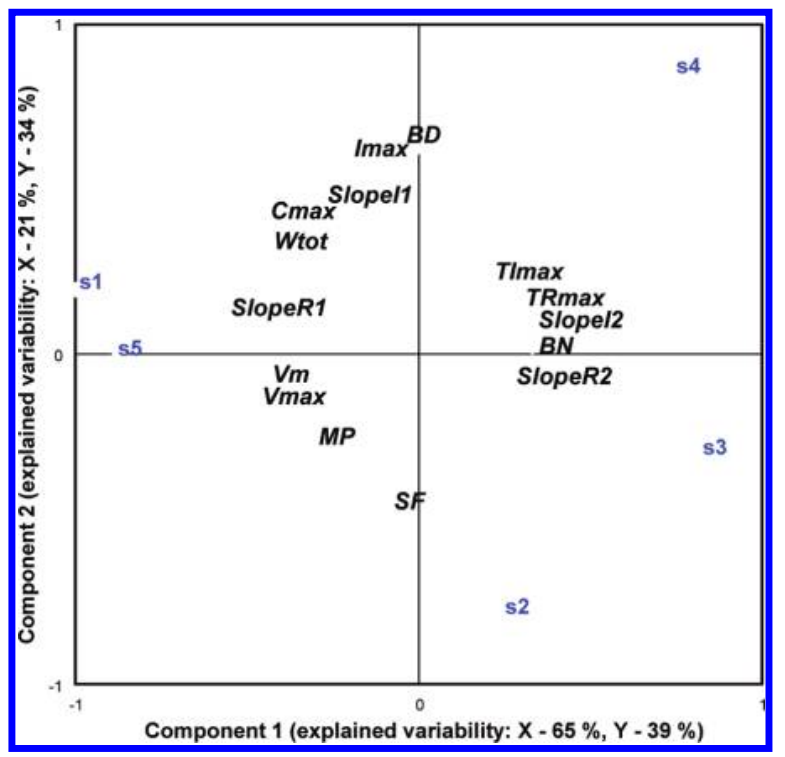

Figure 4. Partial least-squares method explaining saltiness parameters in terms of chewing parameters. Parameters: burst duration (BD), mean and maximum amplitudes (Vm and Vmax, respectively), total muscle work (Wtot), number of bursts (BN), salivary flow rate (SF), masticatory performance (MP), maximum sodium release (Cmax), maximum saltiness (Imax), time to reach the maximum sodium concentration (TRmax), time to reach maximum saltiness (TImax), initial sodium released between 0 and $20 \mathrm{~s}$ (slopeR 1 ), initial saltiness between 0 and $20 \mathrm{~s}$ (slopeI1), persistence of sodium in saliva (slopeR2), persistence of saltiness (slopeI2), and subject (s1-s5).

hypothesis, PCA was applied to the mean values obtained in averaging all subject values for each chewing parameters (Figure 5). Wtot, Vm, Vmax, Wc, and $\mathrm{BD}$ appeared to be highly correlated, and they were mainly associated with the first component that accounted for $69 \%$ of variability. The second component accounted for $22 \%$ of variability and was associated with BN. The first component separated samples according to

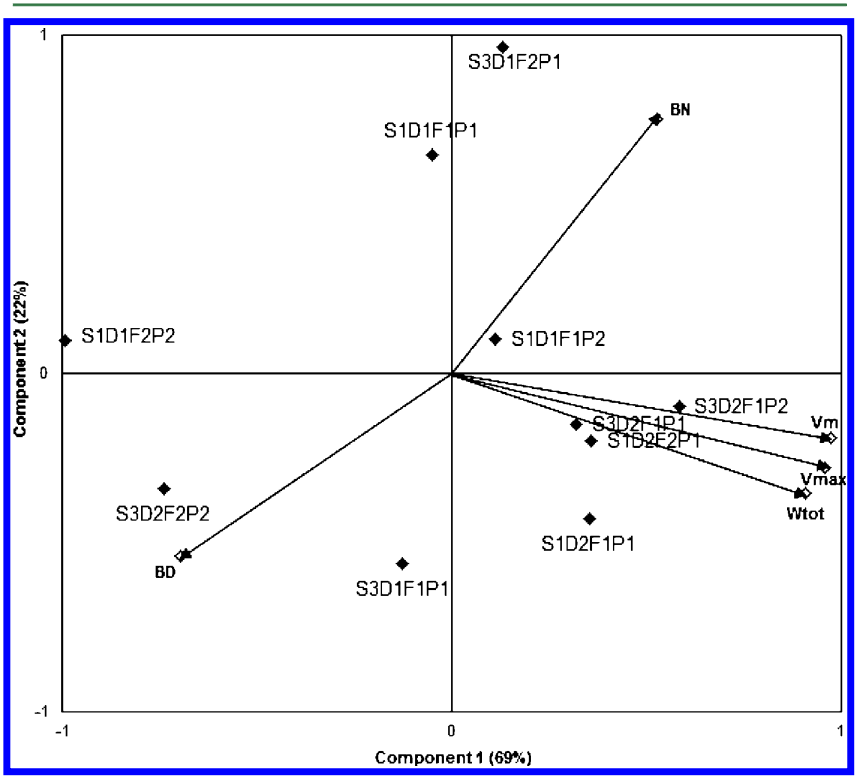

Figure 5. Principal component analysis biplot of chewing parameters obtained with each product. Parameters: burst duration (BD), mean and maximum amplitudes ( $\mathrm{Vm}$ and Vmax, respectively), total muscle work (Wtot), and number of bursts (BN). their composition: high DM content (D2, $440 \mathrm{~g} / \mathrm{kg}$ ), low fat/ $\mathrm{DM}$ ratio $(\mathrm{F} 1,20 \%)$, and low $\mathrm{pH}$ samples $(\mathrm{P} 1,6.2)$ appeared on the right-hand side and low DM content (D1, $370 \mathrm{~g} / \mathrm{kg}$ ), high fat/DM ratio (F2, 40\%), and high $\mathrm{pH}$ samples (P2, 6.5) on the left-hand side. A trend correlation $(r=0.6, p=0.06)$ was found between the first component scores and LPM hardness values, confirming the fact that the amount of work generated to chew the food increased in line with food hardness. ${ }^{30}$

To elucidate how chewing behavior could influence the differences in sodium release and saltiness perception between products, PLS regression was applied separately to each subject and each salt level. A PLS was performed for each salt level because we had previously demonstrated that the impacts of food composition on saltiness perception differed as a function of the amount of salt included in the LPM. ${ }^{4}$

Variable loadings obtained for each salt level in subject 1 are presented as an example in Figure 6. In all subjects, the relationship between sodium release, saltiness perception, and chewing behavior depended on the salt level considered.

At the lower salt level (S1, Figure 6a), chewing work (Vm, Vmax, and Wtot), BN, and BD were positively related to $\mathrm{C}_{\max }$ and Imax on the first component. The first component separated products according to their hardness and their composition. Products with a high DM content (D2), low fat to $\mathrm{DM}$ ratio (F1), and low $\mathrm{pH}$ level (P1) appeared to display lower sodium retention. These products were harder, and the time and work spent on chewing them were higher. We suggest that chewing activity contributed to the increase in sodium release and consequently to the increase in saltiness perception. However, analysis of variance did not reveal a significant effect of the composition factors on maximum sodium release ( $\mathrm{Cmax}$, data not shown) at this salt level. Consequently, it appeared that the increase in chewing activity required for the firmest product resulted in the same amount of sodium being released as with the least firm product, as previously suggested ${ }^{4}$ and observed by others with respect to aroma compounds. ${ }^{14,31}$

The expected increase in sodium release due to the greater mobility of sodium compounds in a softer product may be counteracted in the mouth by the reduction in chewing activity. However, ANOVA revealed a significant masking effect of the fat to DM ratio on saltiness parameters (slopeI1, Imax, slopeI2; $p<0.05$ ), except for TImax, with the most sensitive parameter being Imax. One explanation is that a higher fat level may have created a barrier between the aqueous phase and taste receptors. ${ }^{32}$ Another hypothesis could be that texture or fat perception interacted with saltiness perception when perceptive signals are integrated in the brain. Perceptive interactions between texture and flavor perceptions have already been reported. ${ }^{33}$ Specific receptors for fat are hypothesized in humans, and fat perception is now considered to be a specific taste. $^{34}$ The second component mainly separated low and high fat contents. Products with a higher fat level (F2) resulted in a longer persistence of saltiness in the mouth, and a longer time is required to reach maximum saltiness.

At the higher salt level (S3, Figure 6b), chewing work (Vm, Vmax, and Wtot), BN, and $\mathrm{BD}$ were negatively related to Cmax, slopeR1, slopeI2, and TImax and positively related to Imax, slopeI1, and slopeR2 in the first component. The first component mainly separated low and high DM ratios. Samples with high DM content (D2) were harder, and the time and work expended on chewing them were higher. An LPM with a low DM content (D1) displayed lower sodium retention due to the reduction in the casein content, which caused a higher 


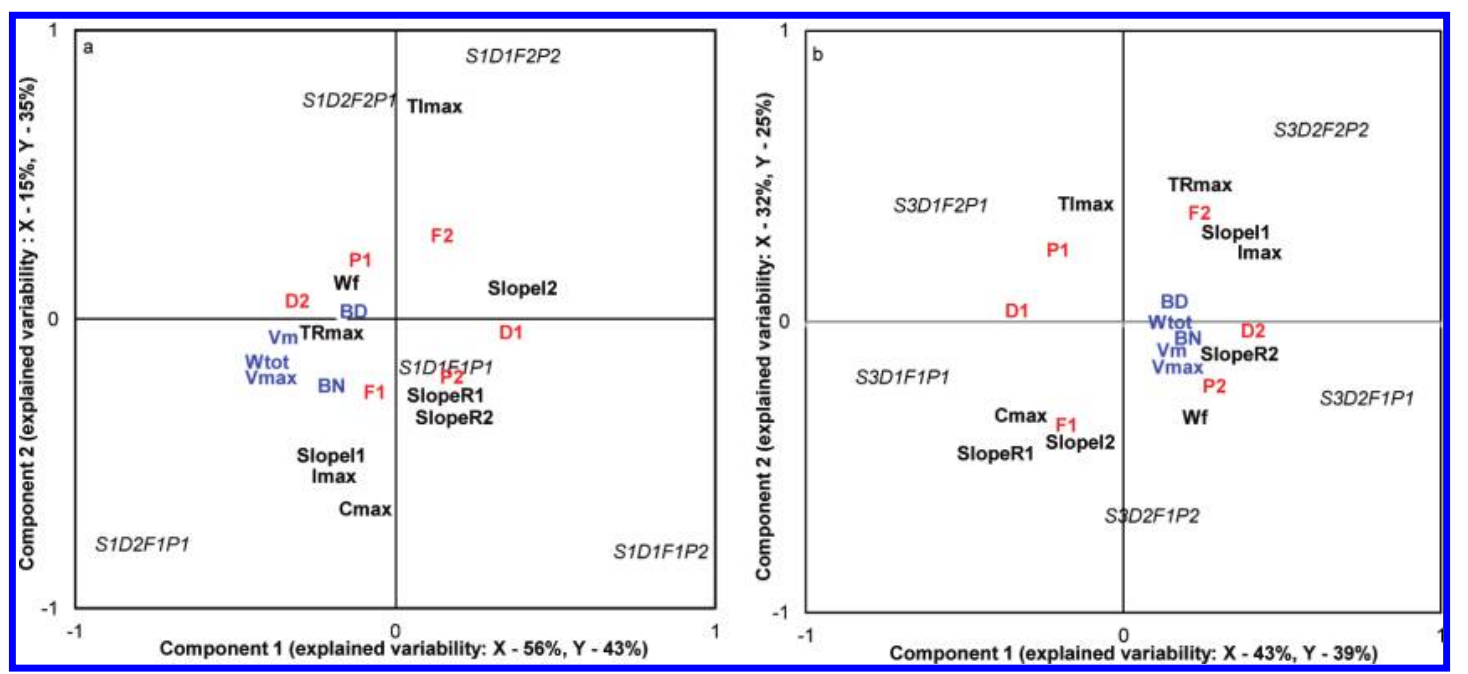

Figure 6. Partial least-squares method for subject 1 explaining saltiness parameters in terms of chewing parameters and lipoprotein matrix characteristics for products with a low salt level (S1, 0.5\%, panel a) and with a high salt level (S3, 1.5\%, panel b). Parameters: masticatory performance (MP), salivary flow-rate (SF), Burst duration (BD), mean and maximum amplitudes (Vm and Vmax, respectively), total muscle work (Wtot), number of bursts (BN), work to the fracture (Wf), maximum sodium release (Cmax), maximum saltiness intensity (Imax), time to reach the maximum sodium concentration (TRmax), time to reach maximum saltiness (TImax), initial sodium released between 0 and $20 \mathrm{~s}$ (slopeR1), initial saltiness between 0 and $20 \mathrm{~s}$ (slopeI1), persistence of sodium in the saliva (slopeR2), and persistence of saltiness (slopeI2). D2, dry matter at $440 \mathrm{~g} /$ $\mathrm{kg}$; D1, dry matter at $370 \mathrm{~g} / \mathrm{kg}$; F2, fat to dry matter (40\%); F1, fat to dry matter (20\%); P2, pH at 6.5; P1, $\mathrm{pH}$ at 6.2 .

availability of sodium in the aqueous phase. ${ }^{24}$ In this case, chewing activity was not the most significant factor with respect to sodium release, which was more markedly affected by composition factors. The second component separated low and high fat to DM ratios. Imax, slopeI1, and TRmax were negatively correlated to Cmax. LPM with a high fat to DM ratio were perceived as being saltier than LPM with a low fat to DM ratio. A similar pattern was observed in all subjects except for subject 2, for whom no significant impact of food composition was seen with the LPM containing a higher salt level.

Thus, a strong relationship between cheese composition, texture, chewing behavior, sodium release, and saltiness was observed. Texture, which varied as a function of composition, influenced both chewing behavior and sodium release, whereas food composition influenced saltiness. Differences in oral parameters (chewing behavior and salivary flow rate) were able to explain most of the variability in sodium release and saltiness parameters among the subjects. Sodium release and salty perception were more influenced by chewing force and salivary flow rate, respectively. A balance between composition and structure needs to be identified to enable the formulation of low-salt foods that take into account health and nutritional guidelines without impairing their acceptability to consumers.

\section{AUTHOR INFORMATION}

\section{Corresponding Author}

* Postal address: Institut National de la Recherche Agronomique, 17 Rue de Sully, F-21000 Dijon, France. Fax: + 33 (0) 380693227. E-mail: salles@dijon.inra.fr.

\section{Funding}

This work was supported by INRA, Regional Council of Burgundy, and Unilever R\&D Vlaardingen.

\section{Notes}

The authors declare no competing financial interest.

\section{REFERENCES}

(1) Lubbers, S. Texture-aroma interactions. In Flavour in Food; Voilley, A., Etiévant, P., Eds.; Woodhead Publishing and CRC Press: Cambridge, U.K., 2006; pp 327-344.

(2) Keast, R.; Dalton, P.; Breslin, P. Flavor interactions at the sensory level. In Flavour Perception; Taylor, A., Roberts, D., Eds.; Blackwell Publishing: Oxford, U.K., 2004; pp 228-255.

(3) Salles, C.; Chagnon, M. C.; Feron, G.; Guichard, E.; Labouré, H.; Morzel, M.; Semon, E.; Tarrega, A.; Yven, C. In-mouth mechanisms leading to flavour release and perception. Crit. Rev Food Sci. 2011, 51, 67-90.

(4) Lawrence, G.; Buchin, S.; Achilleos, C.; Berodier, F.; Septier, C.; Courcoux, P.; Salles, C. In vivo sodium release and saltiness perception in solid lipoprotein matrices. 1. Impact of composition and texture. J. Agric. Food Chem. 2012, DOI: 10.1021/jf204434t.

(5) Pionnier, E.; Chabanet, C.; Mioche, L.; Le Quéré, J. L.; Salles, C. In vivo aroma release during eating of a model cheese: relationships with oral parameters. J. Agric. Food Chem. 2004, 52, 557-564.

(6) Pionnier, E.; Chabanet, C.; Mioche, L.; Taylor, A. J.; Le Queré, J. L.; Salles, C. In vivo nonvolatile release during eating of a model cheese: relationships with oral parameters. J. Agric. Food Chem. 2004, $52,565-571$.

(7) Phan, V. A.; Yven, C.; Lawrence, G.; Chabanet, C.; Reparet, J. M.; Salles, C. In vivo sodium release related to salty perception during eating model cheeses of different textures. Int. Dairy J. 2008, 18, 956963.

(8) Chen, J. Food oral processing - a review. Food Hydrocolloids 2009, 23, 1-25.

(9) Engelen, L.; Fontijn-Tekamp, A.; van der Bilt, A. The influence of product and oral characteristics on swallowing. Arch. Oral Biol. 2005, $50,739-746$.

(10) Kohyama, K.; Mioche, L.; Martin, J.-F. Chewing patterns of various texture foods studied by electromyography in young and ederly populations. J. Texture Stud. 2002, 33, 269-283.

(11) Tarrega, A.; Yven, C.; Semon, E.; Salles, C. Aroma release and chewing activity during eating different model cheeses. Int. Dairy J. 2008, 18, 849-857.

(12) Jack, F. R.; Piggott, J. R.; Paterson, A. Cheddar cheese texture related to salt release during chewing, measured by conductivity preliminary study. J. Food Sci. 1995, 60, 213-217. 
(13) Humphrey, S. P.; Williamson, R. T. A review of saliva: normal composition, flow, and function. J. Prosth. Dent. 2001, 85, 162-169.

(14) van Ruth, S. M.; Buhr, K. Influence of mastication rate on dynamic flavour release analysed by combined model mouth/proton transfer reaction-mass spectrometry. Int. J. Mass Spectrom. 2004, 239, $187-192$.

(15) Guinard, J. X.; Zoumas-Morse, C.; Walchak, C. Relation between parotid saliva flow and composition and the perception of gustatory and trigeminal stimuli in foods. Physiol. Behav. 1998, 63, 109-118.

(16) Fischer, U.; Boulton, R. B.; Noble, A. C. Physiological factors contributing to the variability of sensory assessments: relationship between salivary flow rate and temporal perception of gustatory stimuli. Food Qual. Pref. 1994, 5, 55-64.

(17) Gavião, M. B. D.; van der Bilt, A. Salivary secretion and chewing: stimulatory effects from artificial and natural foods. Scielo 2004, 12, 159-163.

(18) Adam, E. K.; Hoyt, L. T.; Granger, D. A. Diurnal alpha amylase patterns in adolescents: associations with puberty and momentary mood states. Biol. Psychol. 2011, 88, 170-173.

(19) Neyraud, E.; Palicki, O.; Schwartz, C.; Nicklaus, S.; Feron, G. Variability of human saliva composition: possible relationships with fat perception and liking. Arch. Oral Biol. 2012, 57, 556-566.

(20) Mioche, L.; Bourdiol, P.; Martin, J. F.; Noël, Y. Variations in human masseter and temporalis muscle activity related to food texture during free and side-imposed mastication. Arch. Oral Biol. 1999, 44, $1005-1012$.

(21) Neyraud, E.; Prinz, J.; Dransfield, E. $\mathrm{NaCl}$ and sugar release, salivation and taste during mastication of salted chewing gum. Physiol. Behav. 2003, 79, 731-737.

(22) Floury, J.; Camier, B.; Rousseau, F.; Lopez, C.; Tissier, J.-P.; Famelart, M.-H. Reducing salt level in food. Part 1: Factors affecting the manufacture of model cheese systems and their structure-texture relationships. LWT-Food Sci. Technol. 2009, 42, 1611-1620.

(23) Fox, P. F.; Walley, B. F. Influence of sodium chloride on the proteolysis of casein by rennet and by pepsin. J. Dairy Res. 1971, 38, 165-170.

(24) Minéraux et Produits Laitiers; Gaucheron, F., Ed.; Tec \& Doc: Paris, France, 2004.

(25) Van Hooydonk, A. M.; Boerrigter, I. J.; Hagedoorn, H. G. The effect of various cations on the renneting of milk. Neth. Milk Dairy J. 1986, 40, 369-390.

(26) Pionnier, E.; Nicklaus, S.; Chabanet, C.; Mioche, L.; Taylor, A. J.; Le Quéré, J. L.; Salles, C. Flavor perception of a model cheese: relationships with oral and physico-chemical parameters. Food Qual. Pref. 2004, 15, 843-852.

(27) Mialon, V. S.; Ebeler, S. E. Time-intensity measurement of matrix effects on retronasal aroma perception. J. Sensory Stud. 1997, 12, 303-316.

(28) van Ruth, S. M.; Roozen, J. P. Influence of mastication and saliva on aroma release in a model mouth system. Food Chem. 2000, 71, 339-345.

(29) Heinzerling, C. I.; Stieger, M.; Bult, J. F. H.; Smit, G. Individually modified saliva delivery changes the perceived intensity of saltiness and sourness. Chemosens. Percept. 2011, 4, 143-153.

(30) Kohyama, K.; Hatakeyama, E.; Sasaki, T.; Dan, H.; Azuma, T.; Karita, K. Effects of sample hardness on human chewing force: a model study using silicone rubber. Arch. Oral Biol. 2004, 49, 805-816. (31) Gierczynski, I.; Laboure, H.; Guichard, E. In vivo aroma release of milk gels of different hardnesses: inter-individual differences and their consequences on aroma perception. J. Agric. Food Chem. 2008, 56, 1697-1703.

(32) Metcalf, K. L.; Vickers, Z. M. Taste intensities of oil-in-water emulsions with varying fat content. J. Sensory Stud. 2002, 17, 379-390.

(33) Bult, J. H. F.; de Wijk, R. A.; Hummel, T. Investigations on multimodal sensory integration: texture, taste, and ortho- and retronasal olfactory stimuli in concert. Neurosci. Lett. 2007, 411, 6-10.
(34) Besnard, P.; Gaillard, D.; Passilly-Degrace, P.; Martin, C.; Chevrot, M. Fat and taste perception. CAB Rev. Perspect. Agric. Vet. Sci. Nutr. Nat. Resour. 2010, 5, 1-9. 